\title{
Quine's Ontology
}

The Interplay Between Commitment and Decision

\section{Andrei lonuț Mărășoiu}

\section{(2) OpenEdition Journals}

Electronic version

URL: http://journals.openedition.org/ejpap/2243

DOI: 10.4000/ejpap.2243

ISSN: 2036-4091

Publisher

Associazione Pragma

Electronic reference

Andrei lonuț Mărășoiu, «Quine's Ontology », European Journal of Pragmatism and American Philosophy [Online], XII-2 | 2020, Online since 14 December 2020, connection on 15 December 2020. URL : http:// journals.openedition.org/ejpap/2243 ; DOI : https://doi.org/10.4000/ejpap.2243

This text was automatically generated on 15 December 2020.

\section{(c)}

Author retains copyright and grants the European Journal of Pragmatism and American Philosophy right of first publication with the work simultaneously licensed under a Creative Commons AttributionNonCommercial-NoDerivatives 4.0 International License. 


\title{
Quine's Ontology
}

The Interplay Between Commitment and Decision

\author{
Andrei lonuț Mărășoiu
}

\section{AUTHOR'S NOTE}

Acknowledgments: A forerunner of this text was a part of my MA thesis in the History and Philosophy of Science at the University of Bucharest in 2010, advised by professor Mircea Flonta. I owe him a debt of gratitude for his patient guidance and thorough scrutiny. Later versions of the text were also presented at the 3rd congress of the Sociéte de Philosophie des Sciences (Paris, 2009), and the British Society for the Philosophy of Science (Dublin, 2010), and I thank their audiences. I am especially grateful for questions and suggestions coming from prof. James Cargile, dr. Nora Grigore, prof. Pierre Wagner and dr. Ioannis Votsis. In its current form, this work was supported by a grant of the Romanian Ministry of Education and Research, CNCS UEFISCDI, project number PN-III-P1-1.1-PD-2019-0535, within PNCDI III.

\section{Introduction}

1 This paper explores the connections between Quine's ontology and his philosophy of science. I argue in favor of a view not widely shared among Quine scholars, ${ }^{1}$ a view which lays emphasis on Quine's alleged dictum, not to be found in print: "Philosophy of science is philosophy enough." If this is true where Quine is concerned, then its impact on ontology should be brought to the fore.

\section{Metaontology}

According to van Inwagen (2009: 506):

[Quine's criterion of ontological commitment] is a proposal about the way in which "philosophical disputes about what there is" should be conducted. (We might call 
them his "rules for conducting an ontological dispute.") [...] If these "rules" are not followed, then - so say those of us who are adherents of Quine's meta-ontology - it is almost certain that many untoward consequences of the disputed positions will be obscured by imprecision and wishful thinking.

3 For van Inwagen, metaontology is a branch of metaphysics dealing with whether ontological claims are justified, be they either positive (something exists) or negative (something does not exist). Metaontology is also concerned with the extent to which these questions can be raised, and whether there is a principled limit imposed by our language policies (or the human mind's capacities, etc.).

Van Inwagen's approach is representative for a host of philosophical disputes centering around Quine's notion of ontological commitment and how it saves philosophy from the positivistic scruples manifest in, e.g., Carnap (1950). I will return to the question of whether the debate between Quine and Carnap is correctly rendered. I would now like to make two distinct points.

5 The first point is that van Inwagen is correct in pointing out that, for a wide array of ontologists, Quine's criterion of ontological commitment serves as the guiding rule in conducting ontological disputes. This remark made by van Inwagen is both interesting and important. It is interesting because it undercuts classical ontological endeavors such as Heidegger's, for which there is a difference between ontic claims (e.g., those made by scientists) and ontological claims (those made by philosophers, perhaps those especially bent toward Heidegger's thought). Quine's criterion nullifies such differences.

6 A second point, one I will not develop here, since it has been presented at length elsewhere, is that van Inwagen's account and related accounts fail to do justice to Quine's bent toward mathematics and the natural sciences. Here is one relevant passage, owing to Isaacson (2006: 245, 263):

Quine has been quoted as declaring that "philosophy of science is philosophy enough" [...] Peter Strawson attributes this declaration to Quine in Strawson 1982 (p.12) and Strawson 1990 (p.310), on both occasions without reference. Robert Cummins also attributes this declaration to Quine and uses it as the epigraph of his book Meaning and Mental Representation (1990), also without reference. I have been unable to locate this sentence in any of Quine's publications, nor have a number of Quine experts I consulted. However, Strawson's (1990) paper is published with a comment by Quine (CS), and we may suppose that Quine would there have demurred from this imputation to him had he found it alien.

7 If naturalism is to be fully endorsed, as Quine seems to require, it ought to be somehow connected with ontology as well. How is this connection to be achieved? This is the question to which my paper sketches an answer.

\section{Language Policies and Reconstructions as Make- Believe}

8 Carnap and Quine are reputed for reviving the naturalist spirit of Mill after Frege and Russell's philosophical views had been perceived as running against naturalism (Laudan 1987). Is Quine's naturalism a heritage from Carnap? And, given Carnap anontologism, a position according to which ontological questions are meaningless, are there consequently no possible connections between Quine's naturalism (taken over from Carnap) and his ontological views (different from Carnap's full rejection of 
ontology)? More generally, how is their common concern for naturalism to be reconciled with their differences where ontology is at stake? One unorthodox view on the relation between Carnap and Quine comes from Price (2009: 322).

At least in part, then, the contemporary confidence and self-image of metaphysics rests on a conception of its own history in which Quine plays a central role. According to this popular narrative, it was Quine - perhaps Quine alone - who rescued metaphysics from positivism and other threats in those dark days after the Second War (when the World itself seemed at risk). With one hand, Quine wrote "On What There Is," and thus gave Ontology a life-saving transfusion. With the other, he drove a stake through the heart of Carnap's "Empiricism, Semantics and Ontology" (Carnap 1950), and thus dispatched the last incarnation of the Viennese menace [.]

9 I agree with most of Huw Price's remarks, but want to suggest that Quine's position is more nuanced than presented by Price. What follows are two citations, one from Word and Object, the other from "Epistemology Naturalized," at a difference of 8-9 years.

Carnap has long held that the questions of philosophy, when real at all, are questions of language; and the present observation would seem to illustrate his point. He holds that the philosophical questions of what there is are questions of how we may most conveniently fashion our "linguistic framework," and not, as in the case of the wombat or unicorn, questions about extralinguistic reality. He holds that those philosophical questions are only apparently about sorts of objects, and are really pragmatic questions of language policy.

But why should this be true of the philosophical questions and not of theoretical questions generally? Such a distinction of status is of a piece with the notion of analyticity (\$14), and as little to be trusted. After all, theoretical sentences in general are defensible only pragmatically; we can but assess the structural merits of the theory which embraces them along with sentences directly conditioned to multifarious stimulations. How then can Carnap draw a line across this theoretical part and hold that the sentences this side of the line enjoy non-verbal content or meaning in a way that those beyond the line do not? His own appeal to convenience of linguistic framework allows pragmatic connections across the line. What other sort of connection can be asked anywhere, short of direct conditioning to nonverbal stimulations? (Quine 1960: 271)

But why all this creative reconstruction, all this make-believe? The stimulation of his sensory receptors is all the evidence anybody has had to go on, ultimately, in arriving at his picture of the world. Why not just see how this construction really proceeds? Why not settle for psychology? (Quine 1969: 75)

10 At a first reading, these passages seem to go one against the other. In 1960, Quine seeks to generalize Carnap's view that ontological questions are questions of language policy to all statements, observation sentences included. In 1969, Quine seems to change his mind and declare all talk of rational reconstruction and language policy as an uninspired metaphor, a piece of make-believe the theoretical usefulness of which is doubtful and the metaphysical character of which is in contradiction with a commitment to naturalism. On this reading, we may interpret the difference in Quine's thought manifest in the passages drawn from his 1960 and 1969 as a change of mind Quine may have had, as a more severe departure from Carnapian influences, and as a move to a more radical naturalism, not present in Quine's thought in 1960.

11 This first reading seems to me to be mistaken. There are two reasons for being unsatisfied with this reading. First, it makes Quine change his mind on issues crucial to his overall philosophical view, and if we can provide a more conservative picture of Quine, in which he is consistent with himself, such a picture seems superior on 
exegetical grounds. Secondly, notwithstanding the emphasis on naturalism laid by Quine in "Epistemology Naturalized," there is no reason to suppose that anything in Word and Object is opposed to it. To suppose naturalism absent in 1960 is a factual mistake.

Before proposing my alternative reading of these two passages from Quine, I would like to give due credit to an insight present in this first interpretation, namely that, according to Creath (2006: 61):

It could be argued that his preoccupation with reference and ontology generally gave way to a greater concern for issues of an epistemic sort.

\section{Two Problems of Existence}

13 My reading of the way in which the passages cited in Section 3 may be seen as compatible is to distinguish two problems of existence, a semantic problem and an epistemological problem of existence. The semantic problem of existence is this: how can we express what we take there to exist, and what semantic decisions do our forms of expression force upon us, if any? The epistemological problem of existence is this: what criteria do we follow in deciding what we take there to exist, i.e., what are the reliable sources of knowledge in which, in a naturalistic vein, we put our trust? Quine will obviously want to appeal to science, which, fallible as it may be, is still our best guide to learning about and interacting with the world.

On my reading, Quine's remark in 1960 in which he seeks to generalize Carnap's thought applies to the semantic problem of existence, while his remark in 1969 serves to delineate the epistemological problem. Concerning his remark in 1960, it becomes a mere triviality to say that expressing existence by means of certain idioms rather than others is a question of language policies. The question is no longer trivial when it comes to deciding on special cases, such as names without bearers or negative existentials (I will return to these below). Concerning Quine's remark in 1969, it is again short of trivial to say that deciding on existence in a naturalistic frame of mind is to consider rational reconstructions as instruments of limited applicability and utility, and to complete the picture concerning the scientific endeavor with what pertains most to it, a scientific study of science itself, appealing to all relevant sciences, psychology being, of course, one of the sciences to which the appeal made would be the most pertinent.

It is well-known that Quine's philosophy is a good example of how sharp distinctions, such as the one between semantic questions and epistemic questions, are overcome. In fact, the distinction I draw is not that sharp. All it takes is to see that, although the answers may largely overlap, the questions themselves are separated by semantic ascent. A nice illustration of this point, as of the difference between the semantic and the epistemological problem of existence more generally, is the following example from "On What There Is" (Quine 1961: 16):

Translatability of a question into semantic terms is no indication that the question is linguistic. To see Naples is to bear a name which, when prefixed to the words "sees Naples," yields a true sentence; still there is nothing linguistic about seeing Naples.

The distinction between expressing existence and deciding on existence, or, for the moment equating the two, the distinction between the semantic and the 
epistemological problem of existence, is not one I am bringing out for the first time. One relevant Quine scholar is Alex Orenstein, from whose work I extract two relevant passages:

Mastery of the mechanism of demonstrative singular terms and attributive general terms does not make for reference to any new kinds of objects. (Orenstein 2005:

183)

[Quine is] expressing an ontology in terms of the science of logic. (Ibid.: 173)

Orenstein (2005) gives due consideration to the distinction between expressing existence and deciding on existence. In fact, these two give the titles of separate chapters in his monograph. The distinction is also present in Orenstein (2004). The novelty of my paper lies not in introducing the distinction, but in putting a proper emphasis on the role it plays in the interplay between Quine's ontology and his philosophy of science.

Given this distinction between expressing existence (roughly, the semantic problem) and deciding on existence (roughly, the epistemological problem), the question with which I started this paper, namely, what the relation between ontology and philosophy of science is in Quine, can be rephrased by asking how solving the semantic problem relates to solving the epistemological problem.

\section{Methodological Norms for Semantics}

Does expressing existence not bring along some semantic decisions? According to Orenstein, it does, since there are problematic cases such as the following:

(1) Pegasus is fond of green grass.

(2) A flying horse is smarter than reptiles.

(3) There is no bread left in the bakery.

(4) There is no flying horse.

20 These sentences are problematic because we cannot be said to be ontologically committed to objects whose existence is denied, as in negative existentials $(3,4)$, or to putative referents of fictional expressions, also known as "names without bearers," such as "Pegasus" or "a flying horse." How are we to adjudicate between rival ontologies which differ precisely in how they solve these problematic cases?

Regardless of which particular set of solutions for (1-4) we choose, it is manifest that semantic decisions have to be made, decisions on the basis of which the ontology of a theory is to be clearly delineated. By what standards are these decisions to be made? My suggestion is that semantic decisions presuppose methodological norms guiding them. For example, I choose (4), which captures the problems present in (1-3) as well, since it contains both a name without a bearer and a negative existential. (5-7) are solutions given by Quine to (4).

(5) "Flying horse" is an expression which is not satisfied by any $n$-tuple.

(6) It is not true that there is an $x$ such that $x$ is a horse and $x$ can fly.

(7) For all $x, x$ is a horse and $x$ can fly if and only if $x=\varnothing$.

22 These solutions, compiled by Orenstein (1978) and Bencivenga (1986: 373-85), are not the only solutions, to be sure. But they are workable solutions, and the point of invoking them here is that they exemplify the methodological presuppositions of Quine's semantics: these solutions satisfy the requirement of simplicity, consistency 
(something cannot both exist and not exist) and the ontological norms of actuality and literality (fictional characters don't exist).

What I would like to emphasize is not the extent to which Quine's choice of methodology is appropriate or more fruitful than its rivals, but that some methodological choices generally underlie building up a semantics, and that Quine's philosophical views are a good example for how this might be done. Methodological choices can be invoked as reasons for justifying certain semantic decisions, such as, e.g., not allowing flying horses in one's ontology. The mere inexistence of horses with wings is not a logical matter; we have to look into the world and see that there are none. In other words, the expression "flying horse" does not by itself tell us whether it is satisfied by anything. We have to use this expression to make certain statements about the world, statements which usually suppose a background theory in the light of which they are evaluated as true or false. And this background theory is, as we might expect any theory to be, guided by certain methodological rules, rules which are not necessarily prescribed in an a priori fashion, but are read off, and continuously interacting with, the community of practicing scientists.

\section{Yablo's Critique of Quine}

According to Stephen Yablo (1998: 258):

The goal of philosophical ontology is to determine what really exists. Leave out the "really" and there's no philosophy.

If metaphors are to be given special treatment, there had better be a way of telling which statements the metaphors are.

An obvious and immediate consequence is that the traditional ontological program of believing in the entities to which our best theory is committed stands in need of revision. The reason, again, is that our best theory may well include metaphorical sentences (whose literal contents are) not meant to be believed.

Yablo's criticism against Quine is not exhausted by these citations, but these ones focus on the same argument: since there is no criterion for distinguishing between literal (uses of) sentences and metaphorical, or non-literal, (uses of) sentences, and since nonliteral sentences are not meant to carry ontological commitment, the project of reading off ontological commitment from natural language sentences fails.

There are several lines of attack against this argument. I will first list several objections, and them elaborate one of them.

(8) Why suppose Yablo is right, and not bite the bullet and claim our natural language (its ontology included) is metaphorical? (Lakoff \& Johnson 1980).

(9) Yablo does not account for the following intuition: "we do recognize a shift from talk of objects to talk of words as debate progresses from existence of wombats and unicorns to existence of points, miles, classes, and the rest" (Quine 1960: 271).

(10) Yablo's remarks do not apply to formal languages, hence his charges do not apply to Quine: if we read the existential quantifier as ontologically loaded, then whatever we take there not to exist can be handled by means of semantic ascent.

(11) Does Yablo wish to imply ontology ought to be intuitive, or necessarily read off natural language?

The most important of these charges seems to me to be the third, (10). Yablo's remarks, if correct (and we need not assume that they are correct), apply to ordinary language, 
spoken by competent speakers; they do not apply to formal languages. Contrary to Yablo's intentions, his conclusions concerning the impossibility of reading off ontological commitments from natural language discourse is in agreement with Quine's choice of a formal language off which to read commitments, as well as with Quine's thesis of the indeterminacy of translation, which it may be interpreted as supporting. ${ }^{2}$ Here is a relevant passage from Quine (1961: 106).

[I]t is only [...] in reference to one or another real or imagined logical schematization of one or another part or all of science, that we can with full propriety inquire into ontological presuppositions. The philosophical devotees of ordinary language are right in doubting the final adequacy of any criterion of the ontological presuppositions of ordinary language, but they are wrong in supposing that there is no more to be said on the philosophical question of ontological presuppositions.

\section{7. "There is" and an Interpretive Puzzle}

There are three Quinean claims concerning the phrase "there is" which seem to be in conflict with one another.

The first claim is that natural language provides us with the phrase "there is," which Quine says was the original in accordance with which the existential quantifier was codified in standard logic.

Some may protest, however, that the quantifier " $(\exists x)$ " [...] says nothing of entities nor of existence; that the meaning of the so-called existential quantification is completely described merely by the logical rules which govern it. Now I grant that the meaning of quantification is covered by the logical rules; but the meaning which those rules determine is still that which ordinary usage accords to the idioms "there is an entity such that," "an entity exists such that" etc. Such conformity was the logistician's objective when he codified quantification; existential quantification was designed for the role of those common idioms. (Quine 1966: 65)

The second claim is Quine's criterion of ontological commitment, according to which "[t]o be is to be a value of a variable" (Quine 1966: 66). A third claim Quine makes is that ontologizing in natural language is impossible, and was cited above when rejecting Yablo's objections.

But here is the initial puzzle. Don't the three claims conflict? In particular, if the existential quantifier faithfully translates "there is" into canonical notation, then, given that to be is to be a value of an existentially bound variable, shouldn't it also be the case that to be is to be designated by an expression prefixed by the phrase "there is"? If so, wouldn't this amount to saying that natural language is not misfit for reading ontology off its "there is" claims?

2 A plausible answer concerns the phrase "faithfully translates" which appears in the previous paragraph. If indeterminacy of translation applies in the case of regimentation, then there can be no such thing as faithful translation, inasmuch as "where there is one translation, there are many" possible incompatible translations from natural language into or onto standard first-order logic (Quine 1969).

In order to substantiate this claim, any one of two things is required. One thing is to provide translations of "there is" which differ from the existential quantifier. A second thing is to provide translations of the existential quantifier which differ from "there is." 

alternatives to the objectual reading of the existential quantifier which Quine advocates. One such view is Carnap's anontologism (1950), according to which an ontology read off a language (be it natural language or a formalization thereof) is an answer to a nonsensical question. The question concerning the relation between Carnap and Quine's views on ontology is too important to be dealt with here, but prima facie, the common perception of the dispute between the two is that Quine deems ontologizing as a viable question worth pursuing, a question that naturally accompanies the scientific enterprise, while Carnap deems ontology meaningless, a remnant of the metaphysics he had been trying to dispense with since his (Carnap 1932/1959). envisaged by Kripke (1976). Kripke is at pains to emphasize that a substitutional quantification is not devoid of ontological commitments. Such commitments are, in turn, commitments to linguistic entities.

If we recall the Naples example, in which a trip to a foreign city is no particularly linguistic activity, we can see that, irrespective of whether substitutional quantification does have ontological commitments or not, these widely differ from what ordinary competent speakers would take their words to be referring to. The use of substitutional quantification or of mixed objectual and substitutional quantification remains an open alternative, especially for reinterpreting formalized theories, but it is defeated by considerations of intuitiveness in what concerns its application to verbal reports of ordinary speakers.

37 What about the possibility of translating sentences comprising "there is" otherwise than by sentential formulae comprising an existential quantifier? There are several sorts of examples that are relevant in this context. Consider the following statements.

(12) I quit my job, and that is all there is to it.

(13) Being is what there is, what has being exists but is not.

(14) This is an example concerning the phrase "there is."

These examples undermine the idea that "there is" should uniformly be translated as the existential quantifier. (12) comprises the phrase "all there is to it," a saying carrying no ontological load. (12) may perhaps be seen as a rhetorical device. In (14) "there is" is mentioned and not used hence is, according to Quine, referentially opaque (Quine 1960).

39 (13) deserves a brief discussion. It is a mark of the distinction one could make between being and existence, in the manner of Meinong or Heidegger. Quine's opposition to such an existence is manifold. (a) First, there is Quine's second claim cited above according to which the existential quantifier codifies "there is." This claim may be denied by producing counterexamples, or by advancing a completely different hypothesis, such as that there are principially different uses of "there is," one corresponding to existence, and the other to being.

(b) Secondly, Quine opposes such an ontological distinction, which he also identifies as an ontological consequence of both type theories and Carnap's linguistic frameworks, in view of what van Inwagen (2009) has called "the univocality of being." Consider a simple example. There are objects with which we can causally interact; for instance, I causally interact with a cup of coffee every morning. However, there also are abstract 
objects, with which we don't interact, objects the existence of which we posit in order to make true certain statements the truth of which we are persuaded. Is causal efficacy a criterion with respect to which we could divide all there is into two, and say that there are two meanings to "there is," one amounting to causal interaction, the second amounting to theoretical utility? Quine takes a different stand. According to him, as long as we have the predicates "causally efficacious" and "theoretically useful" in our language, there is no need to make "there is" ambiguous; we can let it be true of what each of the predicates is true of taken indiscriminately.

The most serious challenges remain those posed by names without bearers and negative existentials. Traditionally, the intuitive point of negative existentials is to deny existence (ontologically read), not to affirm it. This is not the proper place to discuss the way Quine attempts to solve these problems. (I have suggested in Section 5 that Quine's solutions to these problems, and, more generally, that any solutions to these problems, are methodologically loaded.) What I would like to stress in this section is that Quine's solutions have the advantage of keeping the quantificational idiom as the formal device that best captures the use of "there is" once rhetorical and metaphysical uses are either paraphrased away or ignored as irrelevant for the scientific enterprise within which, and to the benefit of which, Quine devised his notion of ontological commitment by means of bound variables.

It thus seems that there are at least two types of cases in which semantic decision is in order: first, the puzzles in (1-4) in Section 5, and then the rhetorical, metaphysical or conversational uses of "there is" present in (12-14) in this section. These two types of cases suggest that we cannot equate the problem of expressing existence and the semantic problem of existence. In addition to how we decide to express existence (for Quine, this is done in standard logic by means of the quantificational idiom), we also have to decide how we deal with the problematic cases (1-4) and (12-14) and others like them. Semantic decision is inextricably interwoven with expressing what things we take there to exist, and expressing existence always calls for certain local decisions as to what to allow or disallow from the ontology we commit ourselves to.

Well, finally, how are the three claims with which I started this section to be reconciled? On the one hand, the indeterminacy of translation prohibits an unambiguous meaning codified both in the existential quantifier and in the English expression "there is." On the other hand, as (Routley 1966, 1982) correctly points out, Quine identifies existence and objecthood, thus denying Routley's Meinongian claim: "some things do not exist." As expected, there is no simple answer as to how the three claims Quine makes can be reconciled. The beginning of the answer can, I believe, be identified in the following lines from Quine (1981: 9).

The common man's ontology is vague and untidy. [...] Should we regard grammar as decisive? Does every noun demand some array of denotata? Surely not; the nominalizing of verbs is often a mere stylistic variation. But where should we draw the line? It is a wrong question; there is no line to draw. [...] We must recognize this grading off for what it is, and recognize that a fenced ontology is just not implicit in ordinary language. [...] Ontological concern is not a correction of a lay thought and practice; it is foreign to the lay culture, though an outgrowth of it.

What this passage suggests is that the difficulty of reconciling the three claims lies not in Quine's reflections on natural language, but in the workings of that language itself. Ordinary speech is not fit for ontologizing, and it has to be regimented, i.e., translated into standard logic, before it can be used as an adequate tool by the ontologist. This is 
not necessarily a fault of ordinary speech. Our mother tongue may have developed as it has in order to accommodate certain needs and interests of the community of speakers, interests which are different from and perhaps contrary to ontological transparency.

\section{Epistemological Primacy: Truth or Reference?}

If ontology is necessarily connected to semantics, then a choice of semantics is in order. Quine's choice is Tarskian semantics (Quine 1992). This choice itself is not immune from epistemological intrusion. Quine justifies the choice of Tarskian semantics as opposed to, for example, Kripke's account of truth, by appealing to the norm of systematicity of human knowledge as a whole (e.g., Quine's reply to Ullian in Garret and Gibson 1993).

Tarskian semantics, though necessary by Quine's lights, is not enough for ontologizing. First of all, the semantics has to be interpreted as providing formal counterparts of the ordinary language notions of truth, reference and definability. Secondly, Tarski's definition of truth by means of satisfaction provides a clear semantic relation between truth and reference as ordinarily conceived, but is this semantic relation connected to anything in the world? In other words, Tarski's definition of truth leads to solving the semantic problem of existence, but it says nothing about how the epistemological problem of existence might be solved.

How does Tarskian semantics help solve the semantic problem of existence? In an intuitive way, Tarski's definition of truth by means of satisfaction allows Quine to say that we are committed to the existence of those objects that make true the sentences in which the expressions referring to them occur. ${ }^{3}$ The semantic problem of existence is solved by (i) working within Tarskian semantics; (ii) identifying existence, objecthood and reference; and (iii) making the kinds of decisions required by the cases alluded to in Sections 5 and 7.

By way of contrast, the epistemological problem can be rephrased in the following manner: where should epistemology be looked for? Do the findings of science determine what sequences of objects exist, or what sentences the scientific community holds as true? of course, this dilemma may seem far-fetched: once we have one, we are bound to have the other as well. Nevertheless, there is room for philosophical debate, and I will focus on two contemporary philosophers who have illustrated this debate: Quine and P.F. Strawson. Before entering in a more detailed account of their views, I think their positions could be summarized as follows: Quine gives epistemological primacy to truth, while Strawson gives epistemological primacy to reference. Strawson is quite clear on what his stand is; here follow three such statements on his part.

This identificatory task is characteristically the task of the definite singular term.

(Strawson 1968: 399)

So our theoretical grasp of the nature of canonical notation rests upon our theoretical grasp of the identificatory function of singular terms. (Ibid.: 403)

Of course, statements and facts fit. They were made for each other. (Strawson 1950: 137)

Strawson is a redundancy-theorist of truth, as witnessed by the third citation. On a narrower reading, this means that Ramsey equivalences are all there is to know about truth ( $\mathbf{p} \leftrightarrow \mathbf{p}$ is true $\leftrightarrow$ it is true that $\mathbf{p}$ is true, etc.). According to an updated version, truth need not be explicitly defined by satisfaction; we can settle for a partial definition 
of truth by means of instances of the T-Convention (Horwich 1990). But if truth is redundant, it is barred from playing any significant role in epistemology. So this role is given to reference, as witnessed by the first two citations from Strawson.

How about Quine? The principle of context, according to which an expression is meaningful only in the context of a sentence in which it appears, is for Quine one of the milestones of empiricism (Quine 1981). Truth is not only semantically relevant; it is, first and foremost, epistemologically relevant.

\section{Strawson's Objections to Quine. What is the Rationale of Commitment?}

51 One of the most cunning pieces of critique brought against Quine's notion of ontological commitment (in my opinion, at least) is the following.

of course there is a link between the two senses of "object." For objects in the ontological-categorial sense are the basic objects in the logico-grammatical sense. Hard though it is to believe, it is almost impossible not to believe that some confusion of the two senses of "object," or of the two ideas involved, underlies much of the persistent philosophical anxiety that goes under the name of "ontology." The confusion would seem too gross to be credible if it were not for the fact that in philosophy no confusion is too gross to be credible. Worries about Platonism; the talk of "countenancing" items of this or that type or "admitting them into our ontology"; the use of phrases like "a grossly inflated ontology" and the rest - all of these are familiar in connection with quantification into subjectplace, and the connection is very difficult to understand except on the supposition of some such confusion and quite easy to understand on that supposition. (Strawson 2000: 78)

Formulations. Strawson's challenge is not altogether clear. I will attempt two formulations. On the one hand, the criticism seems negative, undermining Quine's empiricism by means of a reductio, basically saying you can't have both empiricism and a semantic conception of existence. On the other hand, Strawson's remarks may also receive a positive formulation, according to which Quine would exhibit some sort of linguistic idealism, couched by Strawson in the telling label "Platonistic myths."

Reply to the negative formulation. As usual, there are replies to both ways of raising the issue. Against the negative side of the objection, one suggesting there is an incompatibility between empiricism and a semantic conception of existence, one may retort that, formulated in the idiom of semantics for the canonical notation, the old metaphysical project is ambiguous. Its heirs are ontology and ideology, where the ontology of a theory couched in standard logic is nothing but the domain of interpretation in a model. Strictly speaking, the ideology of such a theory is the set of predicates needed in the vocabulary to build up the statements comprising the theory. However, one may also comprise, by the term "ideology," definitions and axioms needed to supply the theoretical identification of one set of objects with another. As Quine repeatedly emphasizes, there is room for ontological decision in that a trade-off between ontology and ideology (in the second sense) is always possible.

A simple example for the trade-off between ontology and ideology is the definition of number. We can either assume that there are natural numbers (i.e., abstract objects having certain desirable properties and which are not sets) or we may identify the sequence of natural numbers with a certain sequence of sets in the manner of Frege, 
Zermelo or von Neumann. A definition of number in the sense of this second choice allows us to dispense of our previous commitment to numbers and to get by only with commitment to the sets with which they are identified. This ontological gain is, nonetheless, counterbalanced by a loss in theoretical simplicity, since an inductive definition (say, $(\forall \mathbf{n})\left(\mathbf{n} \in \mathbf{N}^{*} \leftrightarrow \mathbf{n}=\{\mathbf{n}-\mathbf{1}\}\right)$ ) and an explicit definition (say, $\mathbf{0}=\emptyset$ ) have been added.

Given the possibility of this trade-off, one can reply, as Quine does, that empiricism is a question concerning what predicates are to be admitted in one's vocabulary, while the semantic conception of existence is concerned with what elements the domain of a model comprises. Quine can thus justify an intuitively plausible result, namely, that there is no conflict between empiricism and Tarskian semantics: semantics is concerned with what there is (ontology), and empiricism is concerned with how we describe what there is (general epistemology).

Reply to the positive formulation. Perhaps Strawson rejects the idea that what there is can be subjected to ontological decision. This, at least, seems to be suggested by his rejection of the vocabulary comprised of "countenancing" or "accepting" entities into one's ontology. Indeed, Quine's favorite examples are choosing between alternative definitions of number, or between alternative axiomatizations of set theory, or between wave mechanics and particle mechanics etc., and it may be argued that all these decisions are at too high a level of generality to bear on the important and intuitively accessible problems of classical metaphysics: what reality is, what there is. It is obvious that these questions have preoccupied humankind long before these theories were available to us and that naturalizing ontological talk to a semantical or methodological evaluation of such theories might be charged with missing the point.

In brief, Strawson's charges are in fact two, which blend in the expression "linguistic idealism." One part corresponds to semantics, and it is this part which Strawson addresses with his expression "Platonistic myths," and the other part corresponds to empiricism, and it is this part that Strawson addresses when rejecting the vocabulary of "countenancing entities."

But Strawson's remarks seem to presuppose that reality is out there, independent of our making, and immune to ontological decision. In addition, this reality is inaptly characterized as being the end-result of countenancing entities, so it also seems there are proper ways of speaking about reality and improper ways of doing so. Such a view roughly corresponds to a metaphysics which associates one privileged language (typically, natural language) with one world which the language in question merely expresses, describes or depicts, but never changes or mixes with, in a conceptual scheme. I believe Strawson's objection can be challenged by saying that this is by far a more genuine brand of Platonism than Quine's. Contrary to the traditional metaphysical view presented in this paragraph, Quine is both a linguistic and an ontological reconstructivist (in the terminology of Carrara \& Varzi 2001). Whether this position falls prey to other kind of objections than Strawson's, the particular objection formulated in the beginning of this section fails.

\section{Pursuing Truth}

59 There are a number of well-known Quinean arguments in favor of the epistemological primacy of truth and against the epistemological primacy of reference. Quine's thesis of 
ontological relativity (1969), or global structuralism (1992) is one of them. Quine's thesis of the inscrutability of reference is another such doctrine. I will not try to evaluate the extent to which these theses are plausible or even true, but only to speculate on the role they play in Quine's thought. In the light of the previous sections, it seems to me that these theses are negative theses, but that their import is negative only in what concerns the epistemological primacy of reference. In other words, what these theses tell us is that we cannot look into what exists except by looking into which theories of natural sciences are true and which are false. If Quine can both reject the objection coming from Strawson and analyzed in Section 9, and make a case for ontological relativity, for instance, then truth is what connects theories to the world, and not the putative referents of theoretical terms, which are a mere by-product of applying semantics to theories understood as sets of true sentences closed under logical consequence. ${ }^{4}$

But here comes another puzzle: how can the epistemological primacy of truth be reconciled with Quine's disquotationalism? Quine does claim, along with Tarski (1956), that Convention $\mathrm{T}$ is a criterion for the material adequacy of any definition of truth. And Quine (1992: 93) goes on to say that any non-semantic talk of truth is gibberish:

Pilate was probably not the first to ask what truth is, and he was by no means the last. Those who ask it seek something deeper than disquotation, which was the valid residue of the correspondence theory of truth (\$33). Yet there is surely no impugning the disquotation account; no disputing that "Snow is white" is true if and only if snow is white. Moreover, it is a full account: it explicates clearly the truth or falsity of every clear sentence. It is even a more than full account: it imposes a requirement on the truth predicate that is too strong for any predicate within the language concerned - on pain of contradiction [.]

61 If truth is purely disquotational, then it would seem it cannot play the epistemological role I ascribed to it in the preceding sections. I believe, however, that the two positions can be reconciled, and that the key lies in the way the passage cited above continues:

There are recurrent references to a coherence theory of truth, or a pragmatist theory of truth. The question that motivates this quest beyond disquotation can perhaps be phrased thus: if to call a sentence true is simply to affirm it, then how can we tell whether to affirm it?

The lazy answer is "That all depends on what the sentence is. In the case of 'Snow is white' you just look at snow and check the color." The more sympathetic answer is general analysis of the grounds of warranted belief, hence scientific method [...] Truth is one thing, warranted belief another. We can gain clarity and enjoy the sweet simplicity of two-valued logic by heeding the distinction. (Quine 1992: 93-4)

What this text seems to suggest is that truth and warranted belief are, ideally, coextensive notions. It is as if scientists were preoccupied with warranting beliefs, and those beliefs which fared better were declared true. When scientists changed their minds (e.g., due to the falsification of a theory), the sentence is question would no longer be warranted, and the noble tag of truth would thereby be withdrawn.

How does this position solve the epistemological problem of existence? First, given the epistemological primacy of truth, finding out which statements (which theories) are true automatically yields what there is (once the semantic machinery has been brought to bear). Secondly, this is a purely epistemic criterion concerning which sentences are true: the warranted beliefs. Thirdly, this epistemic criterion is just a criterion, and truth receives a purely semantic analysis along the lines of Tarski: Quine is not committed to an epistemic notion of truth such as coherence or the ideal of inquiry. 
There are several comments to be made about this position. First, a historical point: Quine was not prone to talk about warrant. ${ }^{5}$ If we are concerned with the evolution of Quine's thought rather than with the positions he had come to see as satisfactory towards the end of his philosophical career, perhaps the connection between the epistemological and the semantic problem of existence ought to receive a slightly different account. I will not explore this suggestion any further.

Secondly, the notion of warrant that Quine uses does not receive any particular analysis. I am not committed to any such particular analysis, but the following section sketches two ways in which this notion could be made a little more precise in what concerns Quine's approach to the philosophy of science.

\title{
11. How Scientific Practice and Methodological Rules Decide on What There is
}

\author{
According to Price (1992: 406):
}

On one reading, the Quinean doctrine is effectively a principle of ontological quietism - the principle that there is no separate second-order science of ontology, but simply the mundane business of existential quantification carried out by firstorder specialists in the course of their working lives.

67 This is the reading Huw Price favors, although it is not altogether clear whether his remarks are meant to say that this is the way Quine would have had it, or that Quine was mistaken in thinking otherwise that Price. A second reading, one Price dislikes, but which I believe suits Quine better, is depicted in what follows on the same page:

There seems to be a tendency to read the Quinean doctrine in quite a different way, however. Under this second reading, the activities of first-order specialists provide raw data to which the Quinean principle is then applied, yielding second-order ontological conclusions. In other words, the fact that first-order specialists quantify over the entities of a certain kind is held to constitute evidence that such entities actually exist. Far from dismissing the science of ontology, Quine's doctrine thus becomes the main instrument in the working ontologist's tool kit - a kind of "magic eye" for detecting otherwise invisible existents.

I will not quarrel with the magic kit Price mentions, as it is much too familiar a phenomenon that, as Quine (1981: 9) puts it, "ontological concern is foreign to the lay culture." But beyond a certain rhetorical flair, it seems to me that Price provides no serious argument against the possibility that methodological considerations of a far greater degree of generality than any specific scientific finding may indeed play a role in deciding what theories to hold as warranted, hence true, hence indicative of what there is.

In order to flesh out this intuition, I employ Lakatos' terminology. I do this in spite of Lakatos' criticisms of Quine, since I doubt both the accuracy of these criticisms, and that, if they were to be reckoned as true, they applied at all to those aspects of Quine epistemology with which we are concerned in this section. ${ }^{6}$ In line with Quine's view that existence depends on truth, Lakatos (1989: 96) rejects the claim that that sort of metaphysics which is different in kind from methodology should carry any weight in assessing scientific theories.

By metaphysics he [Popper] meant syntactically specifiable statements like "allsome" statements and purely existential statements. No basic statements could conflict with them because of their logical form. For instance, "for all metals there 
is a solvent" would, in this sense, be "metaphysical," while Newton's theory of gravitation, taken in isolation, would not be. [...] I go much further than they [Agassi, Watkins] in blurring the demarcation between [Popper's] "science" and [Popper's] "metaphysics." I do not even use the term "metaphysical" anymore. I only talk about scientific research programmes whose hard core is irrefutable not necessarily because of syntactical but possibly because of methodological reasons which have nothing to do with logical form.

70 Are Quine's views in agreement with Lakatos? To a great extent yes, but not completely. Quine stresses the importance of several norms guiding and regulating the appraisal of scientific theories: conservatism, modesty, simplicity, generality, refutability (Quine \& Ullian 1978: 39-50).

71 However, it seems that the citation from Lakatos condemns the translation of metaphysical questions into syntactic terms, and Quine's dictum, "to be is to be a value of a bound variable," seems to presuppose exactly such a syntactic view. This appearance is deceiving. Although crediting Popper for popularizing fallibilism (1990: V), Quine never endorses a criterion of demarcation, so he does not identify metaphysics as a separate domain of human activity with which he would consequently be at pains to dispense with. The syntactic view used by Popper to back up his criterion of demarcation does not thereby apply to Quine as well.

For Quine, "there is no first philosophy" (1969), and further inquiry into what this means is fruitful only inasmuch as scientific results can, in a naturalistic framework, be used to study the scientific phenomenon itself. Lakatos' ceasing to use the term "metaphysical" is in full agreement with Quine, who declares: "Structure is what matters to a theory, and not the choice of its objects." (Quine 1981: 20).

\section{BIBLIOGRAPHY}

BENCIVENGA Ermano, (1986), "Free Logics," in Don Gabbay \& F. Guethner (eds.), Handbook of Philosophical Logic. Vol. III, Alternatives to Classical Logic, Dordrecht, Reidel, 147-96.

CARNAP Rudolf, (1959 [1932]), “The Elimination of Metaphysics through Logical Analysis of Language," in Alfred Jules Ayer (ed.), Logical Positivism, Glencoe, Free Press.

CARNAP Rudolf, (1967), "Empiricism, Semantics and Ontology," in Paul Benacerraf \& Hilary Putnam (eds.), Philosophy of Mathematics, Oxford, Oxford University Press.

CARRARA Massimiliano \& Achile VARZI, (2001), "Ontological Commitment and Reconstructivism," Erkenntnis, 55 (1), 33-50.

CREATH Richard, (2006), "Quine on the Intelligibility and Relevance of Analyticity," in Roger Gibson (ed.), The Cambridge Companion to Quine, Cambridge, Cambridge University Press, 47-64.

GIBSON Roger, (1980), “Are there really two Quines?,” Erkenntnis, 15, 349-70.

HORWICH Paul, (1990), Truth, Oxford, Oxford University Press. 
ISAACSON Daniel, (2006), “Quine and Logical Positivism," in Roger Gibson (ed.), The Cambridge Companion to Quine, Cambridge, Cambridge University Press, 214-69.

KRIPKE Saul, (1976), “Is There Anything Wrong with Substitutional Quantification?," in Gareth Evans \& John McDowell (eds.), Truth and Meaning: Essays in Semantics, Oxford, Clarendon Press, 324-419.

LAKATOS Imre, (1989), The Methodology of Scientific Research Programmes, ed. John Worrall, Cambridge, Cambridge University Press.

LAKOFF George \& Mark JOHNSON, (1980), “Conceptual Metaphor in Everyday Language,” Journal of Philosophy, 77 (8), 453-86.

LAUDAN Larry, (1987), "Progress or Rationality? Prospects for a Normative Naturalism," American Philosophical Quarterly, 24, 19-31.

LEWIS David, (1983), "New Work for a Theory of Universals," Australasian Journal of Philosophy, 61 (4), 343-77.

ORENSTEIN Alex, (1978), Existence and the Particular Quantifier, Philadelphia, Temple University Press.

ORENSTEIN Alex, (2004), "Reviving a Traditional Concept of Existential Import," Islamic Philosophy and Occidental Views, 9, 253-66.

ORENSTEIN Alex, (2005), Quine, New York, Acumen.

ORENSTEIN Alex, (2008), “Locating Quine's Place in the Naturalistic Tradition," Revue Roumaine de Philosophie, 52 (1), 3-14.

PRICE Huw, (1992), “Metaphysical Pluralism,” The Journal of Philosophy, 89 (8), 387-409.

PRICE Huw, (2009), "Metaphysics after Carnap: The Ghost Who Walks?," in David Chalmers, David Manley \& Ryan Wasserman (eds.), Metametaphysics, Oxford, Clarendon Press, 320-46.

QUINE Willard van Orman, (1960), Word and Object, Cambridge, Ma., The MIT Press.

QUINE Willard van Orman, (1961), From a Logical Point of View: Nine Logico-Philosophical Essays, New York, Harper Torchbooks.

QUINE Willard van Orman, (1966), "A Logistical Approach to the Ontological Problem," in Id., The Ways of Paradox and Other Essays, New York, Harper Torchbooks.

QUINE Willard van Orman, (1969), Ontological Relativity and other essays, New York, Columbia University Press.

QUINE Willard van Orman, (1981), "Empirical Content," Theories and Things, Cambridge, Ma. \& London, The Belknap Press of Harvard University Press.

QUINE Willard van Orman, (1992), Pursuit of Truth, Cambridge, Ma., Harvard University Press. QUINE Willard van Orman, (1992), “Structure and Nature," Journal of Philosophy, 89 (1), 5-9. QUINE Willard van Orman, (1993), “Reply to Ullian,” in Robert Garret \& Roger Gibson (eds.), Perspectives on Quine, New York, Wiley. QUINE Willard van Orman \& Joseph ULLIAN, (1978), The Web of Belief, New York, McGraw-Hill. ROUTLEY Richard, (1966), “Some things do not exist," Notre Dame Journal of Formal Logic, 7 (3), 251-76. 
ROUTLEY Richard, (1982), “On what there is not," Philosophy and Phenomenological Research, 43 (2), 151-77.

SCHAFFER Jonathan, (2008), “Truthmaker Commitments,” Philosophical Studies, 141 (1), 7-19.

STRAWSON Peter, (1950), “Truth-II,” Proceedings of the Aristotelian Society, Supplementary Volume

24, 129-57.

STRAWSON Peter, (1968), "Singular Terms and Predication," Synthese, 19 (1-2), 97-117.

STRAWSON Peter, (2000), Entity and Identity, Oxford, Oxford University Press.

TARSKI Alfred, (1956), “The Concept of Truth in Formalized Languages,” in Id., Logic, Semantics,

Metamathematics, Oxford, Clarendon Press, 152-278.

VAN INWAGEN Peter, (2009), "Being, Existence, and Ontological Commitment," in David Chalmers, David Manley \& Ryan Wasserman (eds.), Metametaphysics, Oxford, Clarendon Press, 472-506.

YABLo Stephen, (1998), "Does Ontology Rest on a Mistake? - I," Proceedings of the Aristotelian Society, Supplementary Volume 72, 229-61.

\section{NOTES}

1. The story behind the dictum attributed to Quine that I mention below is recounted by Isaacson (2006). In saying my interpretation of Quine is not widely shared among Quine scholars, I mean to point to the differences between interpreting Quine as a forerunner of, say, work done by Paul and Patricia Churchland and Daniel Dennett, and the Quine from whom Peter van Inwagen and other avowed metaphysicians take inspiration. To be sure, Quine is the one and the same philosopher. But metaphysicians and philosophers of science emphasize different aspects of Quines' views. Gibson (1980) is a useful early discussion of attempting to reconcile different strands of Quine's overall outlook. See also the discussion of Huw Price's reassessment of the literature in Section 3 below.

2. Yablo offers the argument coming from his criterion of literality to rebut Quine's allegedly analogous argument against Carnap's conventionalism in the philosophy of mathematics. Nothing I have said favors either Quine or Carnap in that naturalistic debate.

3. Strictly speaking, this is not a proper account of Quine's criterion of ontological commitment, since it does not discriminate between Quine and those claiming that existence supervenes on truth (e.g., Schaffer 2008), nor between Quine and Orenstein (2004), who offers a criterion of ontological commitment according to which to be is to make true an (affirmative) elementary sentence. These discriminations are downplayed because they do not influence the course of the argument made in this paper.

4. It may be urged that Quine's concept of what a scientific theory is has changed over time, getting closer to a semantic view of scientific theories. This may be true, but nothing essential of what I say in the paper would thereby have to be modified.

5. I owe this comment to Alvin Goldman.

6. The claim I want to make is that Lakatos' views give a distinctively clear formulation of both a weak variant of holism and a weak variant of naturalism. Concerning holism, Lakatos is at pains to criticize the allegedly conventionalist view of Duhem and Quine. As "Epistemology Naturalized" suggests, this is a far cry from Quine's actual thought. Again, Lakatos argues against an all-encompassing holism, as being incompatible with multiple competing research programmes. But Quine and Ullian (1978) argue that the unit of cognitive significance need not be the whole of our language or knowledge, but a large part thereof. If we consider research 
programmes in areas which are basic enough for research so as to provide the background theories of various special sciences, this concession is enough to make many aspects of Lakatos' account apply to Quine's views as well.

7. The last two interpolations belong to Lakatos' editors.

\section{ABSTRACTS}

This paper elaborates on the relation between Quine's notion of ontological commitment and his philosophy of science. I distinguish and present Quine's solutions to two problems of existence, a semantic problem, roughly amounting to asking how existence can be expressed within a certain language, and an epistemological problem, roughly amounting to how the members of the scientific community can decide which theories are warranted. The gap between these problems is filled by noticing that existence is equated by Quine with reference, and that the principle of context imposes the epistemological primacy of truth over reference. Truth, in its turn, albeit given a purely semantic account along the lines of Tarski, is coextensive with the notion of warranted belief.

\section{AUTHOR}

\section{ANDREI IONUȚ MĂRĂȘOIU}

University of Bucharest

andrei.marasoiu[at]filosofie.unibuc.ro 